\section{Arqueologia Guarani na ponta sul do Brasil}

\author{
Por Bruno Leonardo Ricardo Ribeiro \\ Universidade Federal de Pelotas \\ (brunoleo.ribeiro@gmail.com)
}

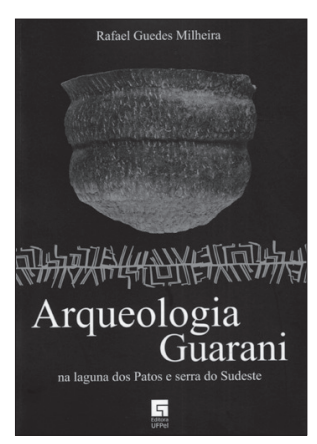

MILHEIRA, Rafael.

Arqueologia Guarani na laguna dos Patos e serra do Sudeste. Pelotas: Editora da Universidade Federal de Pelotas, 2014. 306 p. ISBN 978-857192-947-0.

Este livro é uma versão revisada da dissertação de mestrado de Rafael Guedes Milheira, composto por sete capítulos e prefácio de Paulo DeBlasis. A importância da obra é ressaltada já no prefácio, por ser a primeira a, de fato, sistematizar a ocupação Guarani no extremo sul do Brasil, mais precisamente na área entre a laguna dos Patos, a leste, e a região serrana, a oeste. Lançando mão de uma metodologia de enfoque regional, Milheira conseguiu realizar uma pesquisa arqueológica que possibilita o diálogo com a Antropologia e a História, além da "construção de uma História indígena propriamente dita" (p. 20), o que torna seu livro indispensável para aqueles que procuram estudar as ocupações Guarani no sul do Brasil, sejam eles especialistas da área ou estudantes.

$\mathrm{Na}$ introdução, Milheira informa que sua principal motivação para a pesquisa partiu da constatação da quase completa ausência de registros históricos que fizessem referência à participação da cultura indígena na formação identitária regional, relegando às populações indígenas um papel secundário e marginal no processo de construção social local. Ainda, e à contramão dos registros históricos, os achados arqueológicos atestam a presença significativa de variadas populações indígenas na região, envolvidas em um complexo sistema de relações e redes sociais que remetem a mais de 2.500 anos, sistematicamente eliminadas física e culturalmente desde a chegada dos primeiros colonizadores europeus. Mesmo que não levados ao completo extermínio, hoje ainda reside na região apenas uma parcela ínfima do que antes foi uma nação indígena sem precedentes.

Os dois primeiros capítulos são fundamentais para a compreensão da obra e da proposta do autor, e neles é apresentado um panorama geral da arqueologia Guarani, desde as primeiras pesquisas realizadas não apenas na área de estudo, mas também aquelas relacionadas às ocupações caracterizadas como pertencentes a este grupo em várias regiões do Brasil. É dada ênfase aos estudos realizados por Alfred Métraux na primeira metade do século $X X$ e sua contribuição à formação do pensamento arqueológico brasileiro sobre os Guaranis, como as proposições que fez sobre a busca guarani pela 'terra sem males' e sobre a zona de fronteira entre os Tupinambás, ao norte, e os Guaranis, ao sul, no interior do estado de São Paulo - proposta posteriormente refinada por Scatamacchia (1990). O autor tece ainda algumas críticas sobre o papel pretensamente apolítico desempenhado pelo Programa Nacional de Pesquisas Arqueológicas (PRONAPA) e seus impactos em estudos posteriores.

Em seguida, partindo de uma proposta que intercala informações em nível micro e macrocontextual, Milheira apresenta temas que vão desde a definição das estruturas arqueológicas pertinentes à interpretação dos dados empíricos por ele levantados - como estruturas funerárias e de combustão - até noções de territorialidade, organização social e expansão, definindo o processo de expansão territorial Guarani como 'enxameamento', conceito

RIBEIRO, Bruno Leonardo Ricardo. Resenha: Arqueologia Guarani na ponta sul do Brasil. Boletim do Museu Paraense Emílio Goeldi. Ciências Humanas, v. 9, n. 2, p. 573-576, maio-ago. 2014. DOI: http://dx.doi.org/10.1590/1981-81222014000200018.

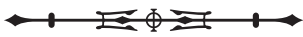


apresentado por Brochado (1984) e amplamente aceito na comunidade acadêmica. Essa definição parte da premissa de que o processo de expansão territorial Guarani foi contínuo, e a ocupação espacial se deu de forma radial, iniciada com uma grande pressão demográfica, que tornou obrigatória uma divisão celular da aldeia e a procura e obtenção por novas áreas de captação de recursos para ocupação e assentamentos permanentes (sobre este assunto, sugiro também o texto de Noelli, 1993).

Esse conceito é fundamental para o entendimento das áreas e dos tipos de atividades relacionados a cada sítio estudado, além de auxiliar na interpretação desses sítios como acampamentos temporários e/ou aldeias. Nessa parte do livro, torna-se claro o exaustivo levantamento bibliográfico realizado pelo autor no que tange à arqueologia Guarani.

Talvez uma única ressalva a ser levantada esteja relacionada ao caráter restritivo da discussão. Apesar de fazer um breve relato sobre o complexo panorama multicultural verificado na região quando da chegada do europeu, então compartilhada por grupos majoritariamente Guarani, mas também por povos Cerriteiros, Jê e Sambaquieiros, a pesquisa de Milheira quase não trespassa a temática Guarani ou extrapola o limite sul do Brasil, nem estabelece um diálogo significativo com pesquisadores ou estudos realizados acima do rio Paranapanema e referentes aos povos Tupi. Acredito que um maior diálogo com tal temática seria muito proveitoso, não apenas para a obra em si, mas também para pesquisadores futuros que utilizarão este livro como referência. Uma vez que Guaranis e Tupis são grupos similares, a ponto de representarem ramificações de um mesmo tronco linguístico ou, para alguns pesquisadores, uma mesma 'tradição' arqueológica, o estabelecimento de contraposições ou a verificação de similaridades, em qualquer nível ou de qualquer caráter, seria mais uma contribuição significativa para a construção do conhecimento arqueológico sobre estas populações de outrora.

No terceiro capítulo, partindo principalmente dos estudos realizados pelo Projeto RADAMBRASIL, o autor faz uma caracterização espacial e geomorfológica da área alvo da pesquisa. Salientando que ela abrange tanto a planície costeira quanto o escudo sul-rio-grandense, descreve sucintamente as paisagens serranas e litorâneas, logo iniciando a apresentação das metodologias adotadas em campo, onde articulou métodos de levantamento probabilístico e oportunístico com a proposta dos estágios múltiplos - reconhecimento geral da área de estudo, levantamento arqueológico, prospecção e escavação. Finalmente, mas não menos importante, Milheira explica sua opção por uma abordagem voltada à arqueologia regional. Sendo seu objetivo compreender o sistema de ocupação Guarani em uma área até então pouco pesquisada, tal enfoque lhe permitiria reconstruir o contexto de implantação dessas ocupações, em seu sentido mais amplo e em seu caráter de longa duração.

Os capítulos quatro e cinco são os mais densos do livro. No quarto, é apresentada a arqueografia de cada um dos sítios identificados ao longo da pesquisa, agrupados de acordo com a fisiografia local - cinco sítios identificados na região litorânea da lagoa dos Patos e dez sítios identificados na região serrana. A apresentação das intervenções realizadas e dos vestígios arqueológicos identificados em cada um destes sítios é extremamente detalhada e minuciosa. Cabe salientar que, sempre que possível, Milheira realiza inferências e proposições acerca da funcionalidade dos contextos arqueológicos verificados em cada um dos sítios, correlacionando suas impressões sobre as escavações com os resultados das análises posteriores.

No capítulo cinco, são apresentados os resultados das análises dos vestígios arqueológicos propriamente ditos. Partindo de uma proposta tecno-tipológica, a metodologia elaborada para a análise dos vestígios cerâmicos é construída principalmente sobre um 'tripé' composto por La Salvia e Brochado (1989), Shepard (1985 [1956]) e Orton et al. (1993). A ficha descritiva e os procedimentos de análise também são detalhadamente apresentados, além de várias páginas serem dedicadas à discussão crítica sobre as potencialidades e as possibilidades de erros relacionados

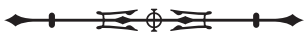


às mais do que comuns projeções de forma, quando elaboradas a partir de fragmentos cerâmicos de tamanhos diminutos. A primazia verificada nesta seção da obra é sem igual, assim como a confiabilidade dos resultados obtidos.

Por outro lado, pouca ênfase foi dedicada aos vestígios líticos, possivelmente em função de sua menor recorrência entre os sítios arqueológicos. A metodologia adotada se pauta pela proposta de cadeia operacional sugerida por Schiffer (1972, 1987), e a análise é de caráter tecno-tipológica, embasada principalmente no esquema elaborado por Dias e Hoeltz (1997). Não pude deixar de pensar que os trabalhos de análise dedicados aos materiais líticos foram, em certo grau, muito sucintos, principalmente se comparados aos realizados com os vestígios cerâmicos, e que, talvez, se uma maior profundidade tivesse sido atribuída a eles, como a adoção de uma metodologia embasada em parâmetros tecno-funcionais, apontamentos mais significativos teriam sido alcançados.

Tais estudos tiveram como objetivo não apenas a caracterização destas indústrias líticas e cerâmicas, mas também o levantamento de apontamentos que possibilitassem pensar o domínio e o uso territorial dos Guaranis na região, sobretudo após a constatação do autor de que as matérias-primas identificadas nos sítios litorâneos não estão presentes in loco, e remeteriam a cinco jazidas diferentes, que distam entre 30 e 200 km da Lagoa dos Patos, nas terras altas da serra do sudeste. Vestígios arqueofaunísticos também foram identificados, em baixas quantidades e em estado de conservação insatisfatório, em dois dos sítios escavados na área litorânea. Perante esta baixa relevância, a análise esteve voltada à procura por informações relacionáveis à dieta e às espécies consumidas nos sítios da região, além da procura de possíveis elementos cabíveis de inferências que correlacionassem espécie, apreensão e habitat, e da distribuição espacial dos vestígios com áreas de atividades específicas.

Concluindo a obra, os capítulos seis e sete são dedicados à hipótese elaborada para a ocupação territorial da área-alvo pelos Guaranis e à apresentação do modelo interpretativo adotado pelo autor. Embasado majoritariamente na perspectiva sistêmica de Binford (1980, 1991 [1983]) e no modelo de ocupação proposto por Noelli (1993), Milheira pressupõe a existência de um contexto macroespacial, onde todos os sítios estudados, sejam eles entendidos como aldeias ou acampamentos temporários, estão interligados por uma imbricada rede de relações sociais, ideológicas, ambientais e econômicas. Tal contexto seria o do 'Teko'a do Arroio Pelotas', abrangeria aproximados $35 \mathrm{~km}$ de raio e se dividiria em litoral e serra, não apenas pelo tipo de ambiente ocupado, mas também pelas modalidades e características de cada assentamento verificado - além do domínio territorial projetado.

Segundo o autor, estes dois ambientes de ocupação estariam intrinsecamente interligados, sendo a porção litorânea uma extensão da porção serrana. As ocupações da região serrana apresentam distribuição espacial mais aglomerada, maiores dimensões e remetem a períodos mais antigos. Estão situadas em áreas de melhor acesso a recursos naturais e mais propensas à agricultura. As ocupações da porção litorânea, por sua vez, seriam mais recentes e periféricas às ocupações serranas, de distribuição mais esparsa e voltadas à obtenção de recursos marítimos. Seriam oriundas da necessidade por novos territórios, em função de pressões demográficas e do processo de expansão por enxameamento, e apresentariam certo grau de dependência em relação às aldeias serranas centrais (em relação à obtenção de matérias-primas líticas, por exemplo).

Não posso deixar de exaltar os esforços realizados por Milheira em relação ao levantamento das fontes de matéria-prima e à correlação perspicaz entre as distâncias, o estabelecimento de redes de troca e o ciclo de vida dos instrumentos líticos. Isso é algo de extrema importância para a interpretação e distinção relacionadas à funcionalidade de determinados acampamentos litorâneos e à organização do ‘Teko'a do Arroio Pelotas' em nível Guará, uma vez que, segundo sua hipótese, apenas uma das cinco jazidas de matérias-primas estaria dentro dos limites deste 'Teko'a', o que

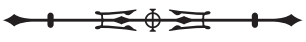


demandaria, obrigatoriamente, outras formas de obtenção das matérias-primas, além do simples aprovisionamento.

Por fim, elogios devem ser feitos ao autor pela utilização de verbetes êmicos Guarani, retirados de leituras etno-históricas e utilizados ao longo de toda a obra, mas principalmente ao nomear as funções exercidas pelos instrumentos líticos, quando inova ao apresentar a outros pesquisadores interessados em estudos similares as possibilidades de um diálogo etnográfico, como há muito vem sendo realizado entre aqueles que estudam cerâmica arqueológica.

\section{REFERÊNCIAS}

BINFORD, L. R. Em busca do passado: a decodificação do registro arqueológico. Portugal: Europa-América, 1991 [1983].

BINFORD, L. R. Willow smoke and dog's tails: hunter-gatherer settlement systems and archaeological site formation. American Antiquity, Washington, v. 45, p. 4-20, 1980.

BROCHADO, J. P. An ecological model of the spread of potter and agriculture into Eastern South America. 1984. Tese (Doutorado em Antropologia) - University of Illinois, Urbana, 1984.
DIAS, A. S.; HOELTZ, S. E. Proposta metodológica para o estudo de indústrias líticas do Sul do Brasil. Revista do CEPA, Santa Cruz do Sul, v. 25, n. 21, p. 21-62, 1997.

LA SALVIA, F; BROCHADO, J. P. Cerâmica Guarani. Porto Alegre: Posenato e Cultura, 1989.

NOELLI, F. S. Sem Tekohá não há Tekó: em busca de um modelo etnoarqueológico da subsistência e da aldeia Guarani aplicada a uma área de domínio no delta do Jacuí/RS. 1993. Dissertação (Mestrado em História) - Pontifícia Universidade Católica do Rio Grande do Sul, Porto Alegre, 1993.

ORTON, C.; TYERS, P.; VINCE, A. Pottery in archaeology. London: Cambridge University Press, 1993.

SCATAMACCHIA, M. C. M. A tradição policrômica no leste da América do Sul evidenciada pela ocupação Guarani e Tupinambá: fontes arqueológicas e etno-históricas. 1990. Tese (Doutorado em Arqueologia) - Universidade de São Paulo, São Paulo, 1990.

SCHIFFER, M. B. Formation process of the archaeological record. Albuquerque: University of New Mexico Press, 1987.

SCHIFFER, M. B. Archaeological context and systemic context. American Antiquity, Washington, v. 37, n. 2, p. 156-165, 1972.

SHEPARD, A. O. Ceramics for the archaeologist. Washington: Carnegie Institution of Washington, 1985 [1956]. 